\title{
COVID-19 Pandemic: Effect on Confidence Levels of Portuguese Towards People of Different Professions
}

\author{
Miguel Ricou ${ }^{1,2}$ \\ Tiago Pereira ${ }^{3}$ \\ Helena P Pereira ${ }^{1,2}$ \\ Ricardo Picoli ${ }^{4}$ \\ Sílvia Marina ${ }^{1,2}$ \\ 'Department of Community Medicine, \\ Information and Decision in Health of the \\ Faculty of Medicine of University of \\ Porto, Porto, Portugal; ${ }^{2}$ Cintesis-Center \\ for Health Technology and Services \\ Research, Porto, Portugal; ${ }^{3}$ Order of \\ Portuguese Psychologists, Lisbon, \\ Portugal; ${ }^{4}$ Faculty of Philosophy, Science \\ and Letters of Ribeirão Preto at \\ University of Sao Paulo, Sao Paulo, Brazil
}

Correspondence: Sílvia Marina Department of Community Medicine, Information and Decision in Health of the Faculty of Medicine of the University of Porto, Alameda Prof. Hernâni Monteiro, Porto, 4200-519, Portugal

Tel +35I 9198247/3

Email silviamarina@outlook.com
Background: The COVID-19 pandemic is emerging in a world where science is highly developed. Nevertheless, science is not the only resource that people resort to when they have difficulties. In this pandemic context, some professions became more relevant, including front-line professionals, such as medical doctors and nurses, and those who may have an indirect role. The aim of this study is to understand whether there is a strengthening of people's confidence, in politicians, journalists, science-based activities, and in more mystical dimensions.

Methods: A cross-sectional study was carried out to understand the levels of confidence of the Portuguese population in several professional groups, measured in two pandemic moments. Participants were recruited to participate in the study through online platforms. The sample was randomly collected from the Portuguese population. The sample was composed of 1455 Portuguese people with a mean age of 44 years, and 1080 were female. Results: We found high levels of confidence in medical doctors and nurses, as well as in other health professions, science, and education. We detected the opposite trend for politicians and journalists. Measured in two pandemic moments, we found confidence levels in these professionals were lower in September than in July with statistical significance differences [(politicians $(t=3.15, p=0.00)$; journalists $(t=2.49, p=0.01)$ ].

Conclusion: It is important to improve a joint action between politicians, journalists, health and science professionals to communicate measures to increase confidence from people. There is a need for the engagement of the population in the adoption of protective measures and contribute to easier control in pandemic situations.

Keywords: COVID-19, confidence interval, professions, cross-sectional study

\section{Introduction}

The COVID-19 pandemic has led to an emergency of responses at several levels. In this context, health responses have a central role to play, especially in relation to the prevention and treatment of the disease, ${ }^{1}$ as well as in all dimensions resulting from changes in social and individual life. In addition, several other activities also played an important role in pandemic-related changes and consequences. These changes arise from several prevention strategies to slow the dissemination of the virus. These preventions have enforced numerous restrictions on daily living, including physical distancing and confinement in most countries worldwide. ${ }^{2}$ In this context, there have been several changes in the overall functioning of people, requiring an adaptation of their habits and lifestyles to this new reality, such as tele-schooling and teleworking. ${ }^{3}$ 
In addition, the economic impact on households is also relevant, due to salary reduction or unemployment. ${ }^{4}$

In Portugal, to control the number of cases of infection, the government announced a state of emergency and established public confinement on March 18, 2020. ${ }^{5}$ Confinement was in place between March 19 and May 1. ${ }^{6,7}$ Several activities have been temporarily closed, others have changed their forms of care, avoiding physical contact. Several changes have been observed in all working and scientific areas, requiring confidence, adaptation, and investment by different groups of professionals in order to help people.

Some professions became more relevant in the context of the COVID-19 pandemic, including front-line professionals, such as medical doctors and nurses, mental health specialists helping people deal with the several pandemic consequences, and those who may have an indirect role, like lawyers and economists. ${ }^{8}$ Journalists and politicians also play an important role in this context. ${ }^{9}$

With the novel coronavirus, there has been mass circulation of news that reaches nearly every country on Earth. ${ }^{10}$ In a context of a crisis such as COVID-19, with massive and daily production of science, the dissemination of information to the people is vital, making them aware of the problems and helping them to protect themselves and others. Journalism is the key to providing credible, unbiased, and understandable information to combat myths and rumors created around falsehoods and misinformation. ${ }^{11}$ However, confidence from people in these professionals seems to be affected by fake news, communication problems, and conspiracy theories. ${ }^{12,13}$

Politicians also play an important role in response to COVID-19, which has been driven mainly by national governments and public health authorities. ${ }^{14}$ Protective measures and governmental restrictions during pandemics are examples of some decisions made by politicians to prevent virus spread. ${ }^{1}$ Confidence in the government plays a crucial role in the adoption and the adherence of these protective measures. ${ }^{15}$ However, trust in politicians might only be one aspect of trust. ${ }^{9}$ To increase confidence, people also need relevant scientific experts. ${ }^{16}$ A survey conducted during the COVID-19 pandemic in Germany showed that most people were more likely to trust scientists than politicians. ${ }^{17}$ Likewise, a study by Okuhara et $\mathrm{al}^{18}$ found that people had more confidence in doctors than in any other agents.

Low perception of the risk of contagion can also have an influence on confidence, leading people to adopt less preventive behaviors. ${ }^{19,20}$ Fatigue, defined by the $\mathrm{WHO}^{21}$ as "pandemic fatigue", can also have an important role in a pandemic.
It is expressed through people's reduced effort to comply with preventive measures and a low-risk perception. $^{21}$

This is the first major pandemic of the 21 st century. The last major and global phenomenon of this kind was the pneumonic plague at the beginning of the 20th century. Science today is significantly different, being faster, global, and closer to people. People need explanations to better understand the reality in their lives. These explanations can be based on mysticism, such as punishment or destiny, or they can assume more scientific dimensions. ${ }^{22}$ We live in a post-modern era where objective science is no longer the main paradigm. ${ }^{23}$ Postmodernists deny that there are aspects of reality that are merely objective, that these aspects of reality can be considered objectively true or false, and that there are objective or absolute moral values. $^{23}$ Thus, science also gives space to other beliefs, mystical solutions, and other philosophies.

The COVID-19 pandemic is emerging in a world where science is highly developed. It is, then, possible that people strengthen their confidence in science and its professionals, thus gaining importance in their lives. ${ }^{24}$ Nevertheless, science is not the only resource that people resort to when they have difficulties. There are also other popular activities to which people can appeal, both those considered more spiritual and those based on other kinds of beliefs. It is important to know how much this affects people's confidence in science, in particular the degree of confidence of the Portuguese citizens in professions and in other activities. Thus, the main purpose of this study is to understand whether there is a strengthening of people's confidence, measured in two pandemic moments, in politicians, journalists, and science-based activities, and whether this pandemic reinforces people's confidence in more mystical dimensions.

\section{Materials and Methods}

To understand the levels of confidence of the Portuguese population in professional groups and other activities with a direct or indirect role in the COVID-19 pandemic, a cross-sectional study was carried out. We defined as a research question: does the covid-19 pandemic influence the levels of confidence of the Portuguese in different professional groups with a direct and indirect role in the management of the pandemic?

\section{Participants}

The sample was randomly collected from the Portuguese population. The sample was composed of 1455 Portuguese 
people with a mean age of 44 years $(\mathrm{SD}=11.77)$ that ranged between 18 and 79 years $(34.6 \%$ between 18 and 39 years, $55 \%$ in the $40-60$ age range and $10.4 \%$ aged over 61 years) and 1080 were female. Concerning academic qualifications, $15 \%$ had a high school level or less, $42.7 \%$ were university graduates, $32.5 \%$ had master's degrees, and 9.8\% were PhDs.

Participants were recruited by the snowball method. This sampling technique uses reference chains, in which one individual indicates another to participate in the sample. ${ }^{25}$ The inclusion criterion was that participants were Portuguese citizen over 18 years.

\section{Instrument}

To ascertain the level of confidence, a questionnaire with two main questions was created for this purpose. In addition to demographic questions, participants were asked about their degree of confidence in a total of 25 professions and other activities with a direct or indirect role in the COVID-19 pandemic. Responses were given on a fivepoint Likert scale (1, much less confident; 2 , relatively less confident; 3 , no more or less confident; 4 , relatively more confident; 5 , much more confident).

All professionals dealing with physical or mental health illness due to symptoms from COVID-19 were considered professionals with a direct role in the pandemic. All professionals or activities that provided information or are involved in making and communicating decisions were considered to have an indirect role. Three categories of professional groups have been defined: traditional professions, non-conventional therapeutics, and other activities.

The traditional professions with a direct or indirect role in the pandemic selected were: biologists, dentists, medical doctors, economists, journalists, lawyers, nurses, nutritionists, pharmacists, politicians, psychologists, researchers, teachers, and childhood educators. In this study we named all these professions as science-based professions.

For the selection of non-conventional therapeutic techniques, were considered those that have their professional exercise regulated by Portuguese $\mathrm{law}^{26}$ and with a possible direct or indirect role in the pandemic. This category includes: acupuncture, chiropractic, homeopathy, naturopathy, osteopathy, phytotherapy, and traditional Chinese medicine.

The other activities include all popular activities without any regulation and by which their characteristics may have a direct or indirect role in the pandemic (astrology, coaching performed by non-psychologists, meditation, reiki, tarot).
To resolve ambiguities, omissions, and misunderstandings in the questionnaire, a pre-test was carried out with a convenience sample.

\section{Procedures}

To collect the data, the questionnaire was made available to participants by sharing a link through on-line platforms (eg Facebook, LinkedIn). The invitation of new referrals was done by participants themselves. The questionnaire was answered on-line through the Google forms platform. This procedure was selected to increase participation, since national dissemination of the questionnaire was intended. Data collection took place from June 2020 to September 2020.

Procedures were deemed ethical via approval of the study by an independent Ethics Committee (Comissão de Ética Centro Hospitalar S. João/Faculdade de Medina da Universidade do Porto) with the number 164/2020. All procedures performed were in accordance with the 1964 Helsinki Declaration, and its later amendments or comparable ethical standards and the General Protection Data ${ }^{27}$ were followed. Informed consent was obtained from all participants included in the study by selecting a tick box indicating they understood the terms of the study and consented, and the participation in the study was anonymous. No electronic authentication was required.

\section{Data Analysis}

Statistical analysis was performed using Statistical Package for the Social Sciences (IBM SPSS, v. 26.0, Armonk, NY, USA). Descriptive statistical analyses were performed for the characterization of the sample and the confidence variable. Confidence levels, initially collected on a five-point bipolar scale, were recoded into three categories (less confident, no more or less confident, more confident). Skewness and kurtosis values were below 3 and 10, respectively, suggesting no severe deviations from the normal distribution, and therefore, the appropriateness of using parametric procedures. ${ }^{28}$ To determine differences in the confidence between groups, the $t$-test for independent samples was performed. The compared groups were: the first half of July 2020, when Portugal came out of generalized confinement of the population (eg all schools were closed for presential activities since March); September 2020, when people could be less affected by this same confinement and after the holidays period in which the rhythms of life were more similar to the before the pandemic and with less daily new infections. Homogeneity was checked by the 
Levene test, and if the variance was not homogeneous,

$\mathrm{t}$ values for equal variances not assumed were used.

P-values $<0.05$ were considered statistically significant.

\section{Results}

Table 1 displays levels of confidence in the different professional activities. The results point to higher confidence in science-based activities. Medical doctors and nurses seem to be the professional groups that have benefited most from this confidence $(44.7 \%$ and $43.3 \%$ respectively), followed by researchers (37\%), pharmacists $(34.7 \%)$, psychologists $(32.9 \%)$, and teachers and childhood educators $(32.4 \%)$. On the other hand, politicians and journalists are the groups in which the greatest number of participants pointed out as those in who people now have less confidence. Popular or non-

Table I Frequency Analysis for Confidence in Professionals

\begin{tabular}{|c|c|c|c|c|c|c|}
\hline \multirow[t]{2}{*}{ Confidence } & \multicolumn{2}{|c|}{ Less Confident } & \multicolumn{2}{|c|}{ No More or Less Confident } & \multicolumn{2}{|c|}{ More Confident } \\
\hline & $\mathbf{n}$ & $\%$ & $\mathbf{n}$ & $\%$ & $\mathbf{n}$ & $\%$ \\
\hline Acupuncture & 263 & 18.1 & 1102 & 75.7 & 90 & 6.2 \\
\hline Astrology & 302 & 20.8 & IIII & 76.4 & 42 & 2.9 \\
\hline Biologists & 142 & 9.8 & 1033 & 71 & 280 & 19.2 \\
\hline Chiropractic & 262 & 18 & 1137 & 78.1 & 56 & 3.8 \\
\hline Coaching not psychologists & 296 & 20.3 & 1095 & 75.3 & 64 & 4.4 \\
\hline Dentists & 168 & 11.5 & 876 & 60.2 & 411 & 28.2 \\
\hline Economists & 232 & 15.9 & 1080 & 74.2 & 143 & 9.8 \\
\hline Homeopathy & 226 & 15.5 & 1142 & 78.5 & 87 & 6 \\
\hline Journalists & 529 & 36.4 & 739 & 50.8 & 187 & 12.9 \\
\hline Lawyers & 164 & 11.3 & 1161 & 79.8 & 130 & 8.9 \\
\hline Medical doctors & 185 & 12.7 & 620 & 42.6 & 650 & 44.7 \\
\hline Meditation & 185 & 12.7 & 1016 & 69.8 & 254 & 17.5 \\
\hline Naturopathy & 234 & 16.1 & 1117 & 76.8 & 104 & 7.1 \\
\hline Nurses & 167 & 11.5 & 658 & 45.2 & 630 & 43.3 \\
\hline Nutritionists & 158 & 10.9 & 1096 & 75.3 & 201 & 13.8 \\
\hline Osteopathy & 213 & 14.6 & 1098 & 75.5 & 144 & 9.9 \\
\hline Pharmacists & 160 & 11 & 796 & 54.7 & 499 & 34.3 \\
\hline Phytotherapy & 196 & 13.5 & 1144 & 78.6 & 115 & 7.9 \\
\hline Politicians & 655 & 45 & 668 & 45.9 & 132 & 9.1 \\
\hline Psychologists & 136 & 9.3 & $84 I$ & 57.8 & 478 & 32.9 \\
\hline Reiki & 253 & 17.4 & 1091 & 75 & 111 & 7.6 \\
\hline Researchers & 170 & 11.7 & 747 & 51.3 & 538 & 37 \\
\hline Tarot & 323 & 22.2 & 1085 & 74.6 & 47 & 3.2 \\
\hline Teachers and childhood educators & 207 & 14.2 & 777 & 53.4 & 471 & 32.4 \\
\hline Traditional Chinese Medicine & 265 & 18.2 & 1105 & 75.9 & 85 & 5.8 \\
\hline
\end{tabular}

Note: $\mathrm{N}=1455$. 
scientific activities also seem to have suffered a drop in people's confidence (Reiki 7.6\%, Tarot 3.2\%), except for meditation (17.5\%), even if the magnitudes of change were relatively small (Table 1).

In the analysis of the confidence according to two different moments in time, July 2020 and September 2020, we found statistically significant differences between groups.
Table 2 shows statistically significant differences in the confidence in several professional activities between the two periods. The professional activities in which people already had less confidence in the first period [(politicians $(t=3.15, p=0.00)$ and journalists $(t=2.49, p=0.01)]$ were the ones that remained with less confidence in the period after the holidays.

Table 2 Independent Samples $t$-test for Comparison of Groups by Moment of Response

\begin{tabular}{|c|c|c|c|c|c|}
\hline \multirow[t]{2}{*}{ Confidence } & Half of July & September & Total & \multirow[t]{2}{*}{$\mathbf{t}$} & \multirow[t]{2}{*}{$\mathbf{p}$} \\
\hline & MESD & MESD & MESD & & \\
\hline Acupuncture & $1.90 \pm 0.44$ & $1.89 \pm 0.52$ & $1.88 \pm 0.48$ & 0.43 & 0.671 \\
\hline Astrology & $1.83 \pm 0.43$ & $1.8 \mathrm{I} \pm 0.50$ & $1.82 \pm 0.45$ & 0.53 & 0.599 \\
\hline Biologists & $2.11 \pm 0.50$ & $2.03 \pm 0.57$ & $2.09 \pm 0.53$ & 0.63 & 0.030 \\
\hline Chiropractic & $1.85 \pm 0.43$ & $1.85 \pm 0.47$ & $1.86 \pm 0.45$ & 0.02 & 0.982 \\
\hline Coaching not psychologists & $1.84 \pm 0.43$ & $1.80 \pm 0.50$ & $1.84 \pm 0.47$ & 1.14 & 0.256 \\
\hline Dentists & $2.20 \pm 0.56$ & $2.05 \pm 0.62$ & $2.17 \pm 0.61$ & 3.59 & 0.000 \\
\hline Economists & $1.98 \pm 0.47$ & $1.86 \pm 0.55$ & $1.94 \pm 0.50$ & 3.22 & 0.001 \\
\hline Homeopathy & $\mathrm{I} .89 \pm 0.4 \mathrm{I}$ & $1.92 \pm 0.51$ & $1.90 \pm 0.45$ & -0.78 & 0.435 \\
\hline Journalists & $1.79 \pm 0.67$ & $1.67 \pm 0.65$ & $1.76 \pm 0.66$ & 2.49 & 0.013 \\
\hline Lawyers & $2.0 I \pm 0.42$ & $1.95 \pm 0.49$ & $1.98 \pm 0.45$ & 1.88 & 0.061 \\
\hline Medical doctors & $2.38 \pm 0.63$ & $2.13 \pm 0.75$ & $2.32 \pm 0.69$ & 4.98 & 0.000 \\
\hline Meditation & $2.01 \pm 0.52$ & $2.08 \pm 0.57$ & $2.05 \pm 0.55$ & -1.53 & 0.126 \\
\hline Naturopathy & $1.89 \pm 0.45$ & $1.94 \pm 0.54$ & $1.91 \pm 0.47$ & -1.61 & 0.109 \\
\hline Nurses & $2.39 \pm 0.6 \mathrm{I}$ & $2.18 \pm 0.72$ & $2.32 \pm 0.67$ & 4.49 & 0.000 \\
\hline Nutritionists & $2.05 \pm 0.46$ & $2.00 \pm 0.53$ & $2.03 \pm 0.50$ & 1.41 & 0.160 \\
\hline Osteopathy & $1.93 \pm 0.46$ & $1.97 \pm 0.55$ & $1.95 \pm 0.49$ & -1.24 & 0.214 \\
\hline Pharmacists & $2.29 \pm 0.59$ & $2.09 \pm 0.67$ & $2.23 \pm 0.63$ & 4.42 & 0.000 \\
\hline Phytotherapy & $1.94 \pm 0.43$ & $1.96 \pm 0.51$ & $1.94 \pm 0.46$ & -0.62 & 0.534 \\
\hline Politicians & $1.67 \pm 0.64$ & $1.53 \pm 0.60$ & $1.64 \pm 0.64$ & 3.15 & 0.002 \\
\hline Psychologists & $2.25 \pm 0.57$ & $2.20 \pm 0.65$ & $2.24 \pm 0.6 \mathrm{I}$ & 1.04 & 0.300 \\
\hline Reiki & $1.90 \pm 0.45$ & $1.92 \pm 0.53$ & $1.90 \pm 0.49$ & -0.54 & 0.591 \\
\hline Researchers & $2.28 \pm 0.61$ & $2.18 \pm 0.68$ & $2.25 \pm 0.65$ & 2.21 & 0.027 \\
\hline Tarot & $1.82 \pm 0.44$ & $1.79 \pm 0.49$ & $1.81 \pm 0.47$ & 0.91 & 0.363 \\
\hline Teachers and childhood educators & $2.26 \pm 0.61$ & $2.07 \pm 0.71$ & $2.18 \pm 0.66$ & 3.90 & 0.000 \\
\hline Traditional Chinese Medicine & $1.87 \pm 0.44$ & $|.88 \pm 0.5|$ & $1.88 \pm 0.48$ & -0.24 & 0.808 \\
\hline
\end{tabular}

Notes: Mean and standard deviation for each of the groups and for total. Independent Samples $t$-test for comparison of confidence means in professionals by moment of response (Half of July, September). 


\section{Discussion}

We found that the COVID-19 pandemic does not seem to have an influence on people's levels of confidence in most professions. The highest percentage of participants reported having neither more nor less confidence in different professional groups (more than 50\%).

However, more than $40 \%$ of people show higher levels of confidence in medical doctors and nurses, followed by researchers, pharmacists, psychologists, teachers, and childhood education (more than $30 \%$ of participants feel more confident). These results can be justified by the role these professionals play in a pandemic, especially medical doctors and nurses. ${ }^{1}$

Scientific evidence-based professions seem to deserve more confidence from people. It seems possible to argue that in times of crisis and uncertainty, such as the pandemic, people may need to find answers that make them feel safe, and it is often in science that people seek those answers. ${ }^{22}$ Strengthening confidence in science also can be related to scientific and epistemic interdependence in crises and public health challenges. ${ }^{24}$ For example, the role of researchers in the development of a vaccine can be related to the decrease in the level of uncertainty and bringing hope.

Education also played an important role. The implementation of e-learning teaching, from the first level of schooling to university, was fast and minimized the difficulties arising from the closure of educational establishments. ${ }^{3}$ In this way, the efforts of education professionals seem to have deserved high levels of confidence from the participants.

We detected the opposite trend for politicians and journalists. More than $40 \%$ and $36 \%$ of the sample reported feeling less confident in politicians and journalists, respectively. The decrease in confidence in politicians due to the pandemic is also perceived in other countries, such as the United Kingdom. ${ }^{9}$ Also, in the Netherlands and Spain, there has been a decrease in confidence in politicians and mismanagement of the pandemic has been identified as a reason. ${ }^{14}$ People seem to have punished decision-makers and professional messengers in this pandemic crisis. This penalization may be linked to the socio-economic crisis and the measures taken, such as the closure of companies and unemployment. ${ }^{4}$ Likewise, communication failures, misinformation, disinformation, fake news, and conspiracy theories seem to be behind the decline in confidence in journalists. ${ }^{12,13}$

The hypothesis of this study was to assess the confidence levels of people in activities based on scientific evidence and in other activities not based on scientific evidence. Our results show higher levels of confidence in health, science, and education professionals. This is contrasting with a clear trend towards no change in confidence in non-scientific activities, or even a decrease in that confidence. These results are in agreement with previous research on this topic. In Japan, Okuhara et $\mathrm{al}^{18}$ found that messages about security measures (eg encouragement to stay at home) were more followed when communicated by medical doctors. In Germany, the population trusted more in science during the pandemic. ${ }^{17}$

The analysis of confidence levels of people in professionals in two different moments in time (in July after the confinement and in September) shows statistically significant differences in biologists, economists, nurses, pharmacists, researchers, journalists, medical doctors, dentists, politicians, teachers, and childhood educators. Confidence levels in these professionals were lower in September than in July, which seems to indicate a decrease in confidence over time. In Portugal, the number of cases of infection remained stable and low since the leaving of confinement until September. ${ }^{6,7}$ This stability in infections by COVID-19 allowed many people to take holidays, and this might have a role in their perception of risk and fear of infection. This potential decrease in fear and risk perception seems to be related to the feeling of being more secure through health professionals and scientists, ${ }^{19}$ which could lead to a decrease in confidence in professional classes. Taking into account that a higher perception of risk can contribute to health behaviors, ${ }^{20}$ it may occur that people do not see professional counseling with the same need. In addition, the social and potentially economic concerns might start to outweigh the perceived risks related to the virus. ${ }^{21}$ In the same way, the confidence decrease in politicians and journalists can be underlined by those economic concerns with a continued impact in the country. The participants had also lost confidence in economists, and this mistrust is aggravated in the second period evaluated. At the same time, and as pointed out by the $\mathrm{WHO}^{21}$ in relation to pandemic fatigue, the perception of the potential threat of the virus might decrease as people adjust to its existence. Moreover, the communication conveyed to the population often seems to have been perceived as contradictory over time. ${ }^{10}$

These findings highlight the need for a joint action between policymakers, journalists, and health and science professionals, both at the decision-making level and in the communication of the measures to be undertaken. In this way, there can be increased confidence in all professionals engaged in responding to challenges such as those we face today. Increasing confidence in these professionals can lead to an engagement of the population in the adoption of protective 
measures and contribute to easier control in pandemic situations.

Some limitations must be considered. The size of the sample is not representative of the Portuguese population, and the results cannot be generalized. In addition, participants were not the same in the different periods analyzed. Also, the economic level or the degree of affectation experienced by the participants can be considered. This issue can be taking into consideration in future research, since the perception of aspects related to the pandemic can vary greatly depending on the degree of affectation, especially economic. ${ }^{29}$

Future research based on longitudinal studies with the same participants should be carried out. Furthermore, understanding the confidence levels in professionals worldwide could be important to contribute to the standardization of actions in similar situations as the COVID-19 pandemic. A representative sample is also recommended.

\section{Data Sharing Statement}

The data that support the findings of this study are available from the corresponding author [SM], upon reasonable request.

\section{Funding}

This article was supported by National Funds through FCT - Fundação para a Ciência e a Tecnologia, I.P., within CINTESIS, R\&D Unit (reference UIDB/4255/2020).

\section{Disclosure}

The authors report no conflicts of interest in this work.

\section{References}

1. World Health Organization. Mental health and psychosocial considerations during the COVID-19 outbreak, 18 March 2020. World Health Organization; 2020.

2. European Commission. EU Coronavirus response - latest updates. 2020; October, 2020:1-7. Available from: https://ec.europa.eu/commis sion/presscorner/detail/en/FS_20_552. Accessed September 24, 2021.

3. Flores M, Gago M. Teacher education in times of COVID-19 pandemic in Portugal: national, institutional and pedagogical responses. J Educ Teach. 2020;46(4):507-516. doi:10.1080/02607476.2020.1799709

4. Nicola M, Alsafi Z, Sohrabi C, et al. The socio-economic implications of the coronavirus pandemic (COVID-19): a review. Int $J$ Surg. 2020;78:185-193. doi:10.1016/j.ijsu.2020.04.018

5. Presidência da República [Republic Presidency]. Decreto Do Presidente Da República [Presidential Decree] 14-A/2020, 2020-03-18- DRE; 2020:13-15. Available from: https://dre.pt/web/guest/home/-/dre/ 130399862/details/maximized. Accessed September 24, 2021.

6. Presidência do Conselho de Ministros [Presidency of the Council of Ministers]. Resolução do conselho de ministros [Resolution of the Council of Ministers] n. ${ }^{\circ}$ 33-C/2020; 2020:7-23.

7. DGS, Direção Geral da Saúde [Directorate General of Health]. Covid19 relatório de situação 30 Setembro [Covid-19 Progress report September 30] 2020; 2020.
8. Oliveira M, Fernandes C. Managing the Coronavirus pandemic in Portugal: a step-by-step adjustment of health and social services. Psychol Trauma. 2020;12(5):536-538. doi:10.1037/tra0000879

9. Fancourt D, Steptoe A, Wright L. The Cummings effect: politics, trust, and behaviours during the COVID-19 pandemic. Lancet. 2020;396(10249):464-465. doi:10.1016/S0140-6736(20)31690-1

10. Balog-Way DHP, McComas KA. COVID-19: reflections on trust, tradeoffs, and preparedness. J Risk Res. 2020;23(7-8):1-11. doi:10.1080/13669877.2020.1758192

11. UNESCO. Press Freedom and Censorship; 2020. Available from: https://en.unesco.org/sites/default/files/unesco_covid_brief_en.pdf. Accessed September 24, 2021.

12. Jutzi CA, Willardt R, Schmid PC, Jonas E. Between conspiracy beliefs, ingroup bias, and system justification: how people use defense strategies to cope with the threat of COVID-19. Front Psychol. 2020;11:1-16. doi:10.3389/fpsyg.2020.578586

13. Lovari A. Spreading (Dis)trust: covid-19 misinformation and government intervention in Italy. Media Commun. 2020;8(2):458-461. doi:10.17645/mac.v8i2.3219

14. Devine D, Gaskell J, Jennings W, Stoker G. Trust and the Coronavirus pandemic: What are the consequences of and for Trust? An early review of the literature. Polit Stud Rev. 2020:1-12. doi:10.1177/1478929920948684

15. Siegrist M, Zingg A. The role of public trust during pandemics: implications for crisis communication. Eur Psychol. 2014;19 (1):23-32. doi:10.1027/1016-9040/a000169

16. Hendriks F, Kienhues D, Bromme R. Trust in science and the science of trust. In: Blöbaum B, editor. Progress in IS. Trust and Communication in a Digitized World: Models and Concepts of Trust Research. Springer International Publishing; 2016:143-159. doi: 10.1007/978-3-319-28059-2_8

17. Wissenschaft im Dialog. Downloads; 2020. Available from: https://www. wissenschaft-im-dialog.de/en/our-projects/science-barometer/sciencebarometer-special-edition-on-corona/. Accessed September 24, 2020.

18. Okuhara T, Okada H, Kiuchi T. Examining persuasive message type to encourage staying at home during the COVID-19 pandemic and social lockdown: a randomized controlled study in Japan. Patient Educ Couns. 2020;103(12):2588-2593. doi:10.1016/j.pec.2020.08.016

19. Breakwell GM, Jaspal R. Identity change, uncertainty and mistrust in relation to fear and risk of COVID-19. J Risk Res. 2020;24(3-4)1-17. doi:10.1080/13669877.2020.1864011

20. Ferrer RA, Klein WMPP. Risk perceptions and health behavior. Curr Opin Psychol. 2015;5:85-89. doi:10.1016/j.copsyc.2015.03.012

21. WHO, World Health Organization. Pandemic fatigue reinvigorating the public to prevent COVID-19; 2020.

22. Rutjens BT, van Harreveld F, van der Pligt J. Step by step: finding compensatory order in science. Curr Dir Psychol Sci. 2013;22 (3):250-255. doi:10.1177/0963721412469810

23. Duignan B. Postmodernism. Available from: https://www.britannica. com/topic/postmodernism-philosophy. Accessed January 31, 2021.

24. Hardwig J. Epistemic dependence. J Philos. 1985;82(7):335-349. doi: $10.2307 / 2026523$

25. Goodman LA. Snowball sampling. Ann Math Stat. 1961;32 (1):148-170. doi:10.1214/aoms/1177705148

26. Assembleia da República [Portuguese Parliament]. Lei n. ${ }^{\circ} 71 / 2013$ de 2 de Setembro [Law n 71 September 2; 2013.

27. European Commission. Regulation (EU) 2016/679 of the European Parliament and of the Council of 27 April 2016. Available from: https://op.europa.eu/en/publication-detail/-/publication/3e485e1511bd-11e6-ba9a-01aa75ed71a1. Accessed January 20, 2020.

28. Kline R. Principles and Practice of Structural Equation Modeling. 3rd ed. New York: The Guilford Press; 2015.

29. Romero-Michel JC, Mokay-Ramírez KA, Delgado-Machuca M, et al. Health and economic measures in response to the COVID-19 pandemic- effect on street vendors. $J$ Infect Dev Ctries. 2021;15 (2):198-203. doi:10.3855/jidc. 13465 


\section{Publish your work in this journal}

Risk Management and Healthcare Policy is an international, peerreviewed, open access journal focusing on all aspects of public health, policy, and preventative measures to promote good health and improve morbidity and mortality in the population. The journal welcomes submitted papers covering original research, basic science, clinical \& epidemiological studies, reviews and evaluations, guidelines, expert opinion and commentary, case reports and extended reports. The manuscript management system is completely online and includes a very quick and fair peer-review system, which is all easy to use. Visit http://www.dovepress.com/testimonials.php to read real quotes from published authors. 